\title{
BLICKDIAGNOSE
}

Stellen Sie uns

Ihren Fall vor.

Bei Veröffentlichung
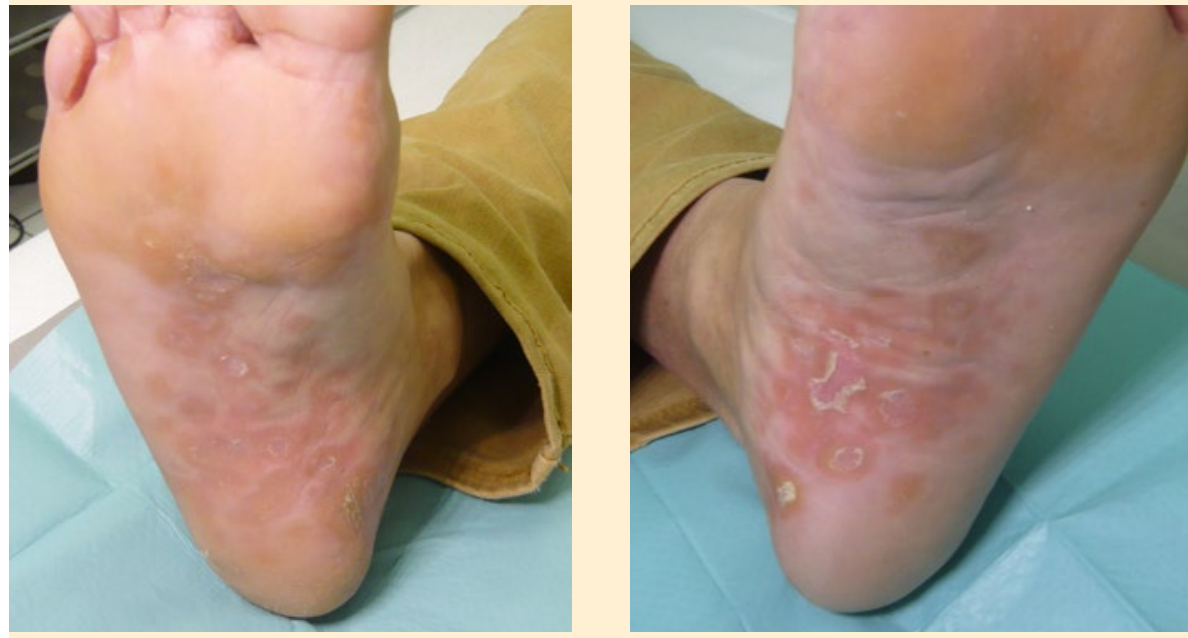

Papulöse Hyperkeratosen an den Handflächen und den Fußsohlen.

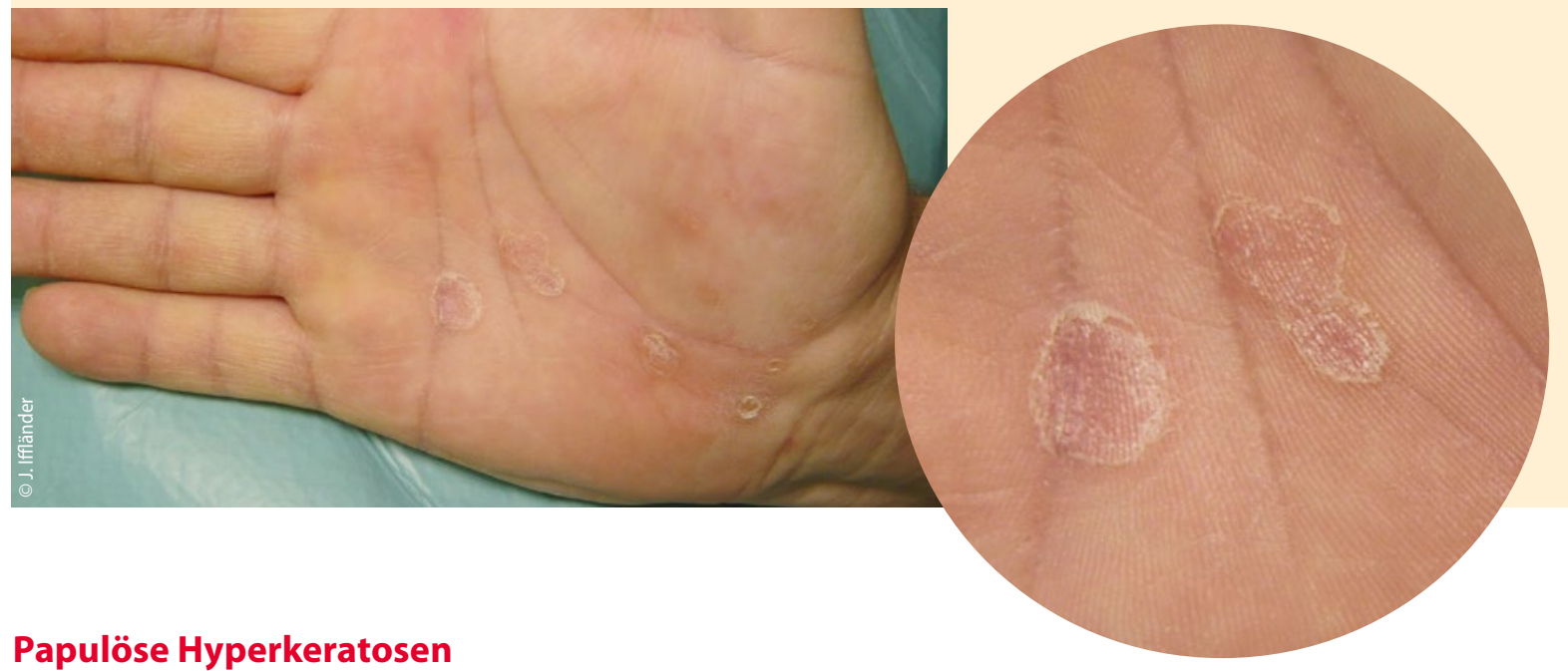

\section{Hat er sich die Schwielen auf der Toilette geholt?}

_ Ein 53-jähriger Fernfahrer stellt sich mit erstmalig aufgetretenen palmaren und plantaren papulösen Hyperkeratosen vor. Weitere Beschwerden liegen nicht vor, auch länger zurückdenkend könne er sich an keine weitere Erkrankung erinnern. Weder Ausschlag noch Fieber, Schwellungen von Lymphknoten oder Abgeschlagenheit hätten jemals vorgelegen. Ich selbst hatte deartige Hautveränderungen zuletzt in den 1980er-Jahren bei einem Syphilis-Patienten gesehen - noch während meiner Assistentenzeit. So richtig wollten sie auch in diesem Fall zu keiner anderen Diagnose passen, weshalb ich eine entsprechende Labordiagnostik veranlasste.

Es ergaben sich eindeutige Zeichen: Der CRP-Wert war stark erhöht bei 23,4 mg/l (normal < 5,0), der VDRL-Test ergab einen Antikörpertiter von 1:32 (normal 1:1) und der Lues-spezifische TPHA-Test einen Titer von 1:10.240 (normal < 1:80). Somit war die Diagnose einer Syphilis gesichert. Es handelt sich dabei um die weltweit zweithäufigste sexuell übertragbare Krankheit. Seit dem 15. Jahrhundert ist sie in Europa dokumentiert. 1905 veröffentlichten Fritz Schaudinn und Erich Hoffmann die Entdeckung des Erregers Treponema pallidum.

Auf den Befund angesprochen verneinte der Patient jegliche Sexualkontakte - er konnte sich lediglich eine Infektion in einer Parkplatztoilette vorstellen. Einem HIV-Test stimmte er zu. Seine Ehefrau wolle er nicht informieren, denn da sei „schon seit Jahren tote Hose“. Behandelt wurde er mit $2 \times 1,2$ Mio. IE Benzylpenicillin-Benzathin (Tardocillin ${ }^{\circledR}$ ) i.m.

Als Fazit sei angemerkt, dass man bei sexuellen Themen lieber nicht allzu sehr auf die Wahrheitsliebe der Patienten bauen sollte.

$\rightarrow$ Dr. med. Jens Iffländer,

Schützenstr. 8, D-14943 Luckenwalde 